\title{
OWNERSHIP AS AN ISSUE IN DATA AND INFORMATION SHARING: A PHILOSOPHICALLY BASED VIEW
}

\author{
Dennis Hart \\ School of Business and Information Management \\ Australian National University \\ dennis.hart@anu.edu.au
}

\begin{abstract}
It has long been an aim of information management and information systems development to enable more effective and efficient data and information sharing within organisations. A commonplace assertion has been that data and information belong, or should belong, to the organisation as a whole as opposed to any individual or stakeholder within it. Nevertheless, despite the potential benefits of data and information sharing within organisations, efforts to achieve it have typically run into more difficulty than expected and have frequently been less successful than the technological capabilities would, at least prima facie, allow. This paper is based on the proposition that perceptions of ownership can have an important influence on data and information sharing behaviour, and explores philosophical theories of ownership and property with the aim of better understanding the origins of such behaviour. It is further proposed that what are here called "implicit" theories of information ownership on the part of different individuals or parties within an organisation can lead to varying perceptions as to who is the legitimate owner of particular data or information, and that this view is illuminating of the difficulties that have often been experienced in trying to achieve effective organisational data and information sharing.
\end{abstract}

\section{INTRODUCTION}

Many modern organisations are critically dependent on their data and information resources for effective and efficient operation. For example, Beynon-Davies (2002, p435) says "Information is a critical resource for organisations, particularly in modern information societies and economies" and consequently, as Applegate, Austin and McFarlan (2003, p1) note, "IT has become a strategic part of most businesses". Reflecting the increasingly critical and strategic nature of data and information, one of the main aims of information management and systems development has been to "ensure that data [and information] with the appropriate quality characteristics ... can be delivered to the right person at the right time in the right form to meet that individual's needs" (Stair \& Reynolds, 1998, p67). But such availability of course implies a willingness to share on the part of those who have the data or information concerned. According to Nolan's (1990) stages of growth model, this is expected to occur in the fifth of the six stages, which is named "Data administration" and which is characterised by, among other things, "shared data".

Despite the claimed benefits of sharing data and information in organisations, and the undoubted and ever increasing capabilities of information technologies to enable it, such sharing evidently remains remarkably problematic. For example, Davenport, et al (1992) say that "the rhetoric and technology of information management have far out-paced the ability of people to understand and agree on what information they need and then to share it [so] the information-based organisation is largely a fantasy" and, arguably, the situation has not changed much since. For example, Kendall \& Kendall (2002, p73), discussing the management of e-commerce projects, say "organisational politics can come into play, because often units feel protective of the data they generate and do not understand the need to share them across the organisation". Various explanations have been put forward to account for these difficulties in achieving organisational data and information sharing, but one issue that, although recognised early (Keen, 1981), has received relatively little attention is that of ownership.

\section{Data and Information Ownership}

The focus of this paper is organizational data and information sharing behaviour and the role issues of ownership play in such behaviour. Accordingly, it is the ownership perceptions of involved parties rather than any formal allocations of "ownership" by external agents or legal issues relating to ownership that are of primary interest here because it seems evident that it is internally felt perceptions of ownership that are likely to drive behaviour at a more fundamental level than any externally or legally imposed ownership might do.

While data and information ownership have been recognised as an issue, particularly with respect to sharing behaviour in an organisational information management and systems development context (e.g. Hart, 1999, Hart \& Whymark, 1999; Koh \& Watson, 1998; Allen \& Wilson, 1996; van Alstyne, et al, 1995; Wigan, 1992), there has apparently been little, if any, attempt to develop a substantive theoretical understanding of the reasons why this should be so. Constant et al (1994) have proposed a theory of information sharing based on social interdependency theory in which they acknowledge the role of "norms of organisational ownership", but do not investigate the foundations or origins of such norms other than to suggest that they arise from work experience and training, and are affected by individual self interest as well as attitudes to reciprocity of behaviour. Moreover, they apparently assume that there is one such ownership norm per organisation and that it influences sharing behaviour generally. Similarly, Jarvenpaa and Staples (2000), who base their work on that of Constant et al, take organisational norms relating to information ownership as one of their independent variables without attempting to explicate its origins. 
This paper explores theories of ownership and the closely related concept of property, in an historical and philosophical sense, in an attempt to understand where the foundations of norms of organisational ownership lie. This exploration is intended to fill in some of the gaps identified above, and it is further contended that the theories of ownership and property investigated have the potential to underpin a better understanding of data and information sharing phenomena of interest and importance in the discipline of information systems. The paper extends the work of Constant et al (1994) by investigating the basis of the organisational ownership norms that they identify as a factor influencing information sharing. In outline, it is argued here that individuals or groups within an organisation hold implicit internal theories of ownership that tell them who owns what and why. These theories could then differ and conflict in their outcomes when applied to the question of who owns certain data or information. Furthermore, data and information are argued to be somewhat different in character from other items that we are used to regarding as being owned, and this adds further complexity and confusion to the issue of who has legitimate ownership of them. Lastly, the implications of the argument for organisational information sharing and conflict over ownership are briefly discussed.

Attentive readers may have noticed that no distinction has so far been made between data and information. It is, however, usual to make such a distinction along the lines that data is a set of uninterpreted symbols whereas information is "data interpreted in some meaningful context” (Beynon-Davies, 2002, p 4). Moreover, it is now also common to differentiate, as separate concepts, knowledge (e.g. Stair \& Reynolds, 1998, p 5-6) and increasingly wisdom (e.g. Liang, 1996) in addition to data and information. But while these distinctions might be valid they will not in most cases be made here because they are, in large part, inessential to the argument to be put forward.

\section{THE CONCEPTS OF OWNERSHIP AND PROPERTY}

The first step in the argument is to consider what it means to "own" something or the closely related question of what it means for something to be "property" (in the sense of private property). There are various views and often differences of detail, but what all have in common is that ownership entails rights (and responsibilities too, but we ignore these) and property is that over which these rights are exercised. The next question, then, is what rights it is that ownership entails. According to Honoré (1961), ownership is "the right to possess, viz. to have exclusive control of a thing, or to have such control as the nature of the thing admits ... and the right to remain in control, viz. the claim that others should not, without permission, interfere". But while any definition of ownership would likely have similar concepts at its core, it is still the case that "all attempts ... to provide a univocal explication of the concept of ownership, applicable within all societies and to all resources, have failed” (Harris, 1996, p5). Even so, as Harris also notes, while the concepts and foundations of ownership and property - that which is or can be owned - might be theoretically elusive, we all still seem to have a well developed intuitive sense of what they mean. And for the most part we operate successfully with this intuitive sense in our ordinary everyday dealings with one another. Nevertheless, we shall here follow Honoré and, while recognizing that ownership has been argued to encompass other significant rights as well as responsibilities, at the very least it entails as its foundation:

- The right to use whatever is owned

- The right to control the use of whatever is owned

- The right to remain in control of whatever is owned, without interference from others.

Indeed, as Carter (1989, p127) says, also quoting Honoré, these characteristics are "perhaps the most central aspect of our conception of private property" and logically therefore, of ownership also.

Now, having briefly considered what ownership and property mean, the question of on what basis ownership is to be assigned arises. That is, on what grounds does ownership of some item of property reside in one set of hands as opposed to another? The attempt to answer this question has occupied philosophers as well as others such as legal theorists over a long period, resulting in a range of different proposals as to the basis of the concepts of ownership and property and it is to the major ones of these that we now turn.

\section{THEORIES OF OWNERSHIP AND PROPERTY}

Theories of property and ownership have a long history dating from at least ancient Greece (Ryan, 1987; Schlatter, 1951) and various philosophical foundations have been proposed as underlying these concepts (Becker, 1977; Grunebaum, 1987). Loosely based on the classification of Becker (1977), the major philosophical bases are, with their originators and principal proponent(s):

- $\quad$ First occupancy theory (Immanuel Kant)

- $\quad$ Labour theory (John Locke)

- Utility theory (Jeremy Bentham, John Stuart Mill)

- $\quad$ Libertarian theory (Robert Nozick, John Rawls)

- $\quad$ Personality theory (Georg Wilhelm Friedrich Hegel)

We now give a very brief thumbnail sketch of each of these foundations in turn. 


\section{First Occupancy Theory}

As the name suggests, first occupancy theory says that ownership is established on the basis of the principle that the initial appropriator of a thing is thereby entitled to it. Any child who ever said: "I had it first, so it's mine!" understands the fundamentals of this theory. There are other issues, of course. In particular, whatever it is that is claimed has first to be unowned; the "occupation" has to be actual as opposed to notional (whatever "actual occupation" may in fact mean); and the bounds of where "occupation" begins and ends need to be clear (Becker, 1977). But despite such points of detail and other complexities that are beyond the scope of this discussion, the basis of the assignment of ownership according to this theory is apparent. Being first to possess or "occupy" whatever the entity in question is, is the basis for its ownership.

\section{Labour Theory}

The labour theory of John Locke can be considered a variant of the first occupancy theory outlined above (Grunebaum, 1987). However, a critical difference is that in the labour theory it is the adding of value through the "mixing" of one's labour with something that confers ownership. The basic premise underlying this theory is that one owns one's person and labour and, therefore, when that labour is applied to something the thing laboured upon thereby moves from an unowned state to an owned one. As Locke says: "The labour that was mine, removing them [the items claimed] out of that common state they were in, hath fixed my Property in them" (Locke, 1689). But, according to Locke, the labour-based claim to ownership has nevertheless to be subject to the requirement that there be "enough, and as good left in common for others" (Locke, 1689). Again, there are complexities and problems relating to how much labour and/or added value is required to confer ownership and how far that ownership extends but, as with the first occupancy theory, the fundamental basis of ownership according to this theory is obvious: one owns the results of one's labour.

\section{Utility Theory}

Utility theories of ownership are founded on the notion that property should be assigned in such a way as to maximise some quantifiable and, at least in principle, calculable "good" (the utility). The same basic principle underlies consequentialist theories of ethics - notably utilitarianism - and a considerable portion of traditional decision theory. Differences arise depending on how utility is defined. Is it an economic concept or a noneconomic one such as happiness, or some combination? While, as Becker $(1977, \mathrm{p} 57)$ notes, the economic view has traditionally taken a higher profile in discussions of utility theory, this is neither necessary nor logical since economic utility is simply a special case of a more general concept of utility. But in any case, the fundamental essence of the theory is the same no matter how utility is conceived: ownership is to be allocated in such a way as to achieve maximum benefit for all involved, whichever way this might be defined and calculated.

\section{Libertarian Theory}

Libertarian theories of ownership are founded on the idea that "a general right to private property is in some sense constitutive of freedom" (Waldron, 1988, p290). Indeed, it has been argued that it "is plausible to construe all rights as property rights" [emphasis in original] (Narveson, 1988, p66). People must, the argument goes, be allowed to establish ownership, though only by just means (Nozick, 1974, p178 et seq), over whatever they want or need because to prevent them from doing so would infringe their liberty in the sense of being able to function effectively as autonomous agents. Liberalism derives from Locke and comes in two main varieties classical liberalism or libertarianism and welfare liberalism (Sterba, 1999). The difference between these is that, in the former, liberty is conceived in terms of the absence of coercions that would restrict one's freedom of action and in particular, in our context, to establish ownership over whatever one requires, albeit without infringing the rights of others in so doing. Nozick's liberalism is of this kind. Welfare liberalism on the other hand asserts that in addition to avoiding actions that would restrict an agent's freedom of action, it is also required to act positively to help them if their ability to act as they wish is below some acceptable minimum. In relation to property, this implies some redistribution in favour of the most disadvantaged may be necessary and there is thus some affinity between this version of liberalism and utilitarian approaches. Rawls' liberalism is of this type (see Rawls, 1971, Chapter V). Nevertheless, the fundamental principle is clearly that property rights are justified by their close and intimate contribution to the liberty of agents to act autonomously, and are to be determined accordingly.

\section{Personality Theory}

In his book The Philosophy of Right Hegel (1821) put forward a theory of ownership and property based on personality. In his words: "A person has as his substantive end the right of putting his will into any and every thing and thereby making it his, because it has no such end in itself and derives its destiny and soul from his will. This is the absolute right of appropriation which man has over all 'things"'. This theory means, as Ryan 
(1984, p122) explains, that it is only humans who have wills and purposes whereas the other stuff of nature is "blankly material and, as it were, 'unoccupied'”. Therefore, the argument goes, a human who invests an object with a purpose through their will to use it for the achievement of some end thereby establishes ownership over it: it becomes their property as a result. There is apparently some affinity here with the first occupancy theory in that ownership presumably resides with the first human to invest the "unoccupied" object with such a purpose. However, there is also an important difference in that the first occupancy theory says nothing of will and purpose whereas this is prime in Hegel's account. The essential feature of this theory is, then, that "propertyowning is [important] since it is only through owning and controlling property that [one] can embody his [or her] will in external objects” (Waldron, 1988, p377-8). It is the agent that invests an object with a purpose who is that object's legitimate owner.

As a simple example highlighting three of the five theories above, consider the case of three people walking together. The first picks up a stick lying beside the path, subsequently just swinging it for a while in rhythm with the pace of the walk before passing it to the second who, when they sit for a rest, proceeds to idly whittle it until it has a sharp point. The third then says "Hey, that would make a really good stake for my tomato plant at home!". According to the first occupancy theory the stick should be the property of the first person whereas the labour theory would accord ownership to the second, and finally the personality theory would vest its ownership with the third.

\section{IMPLICIT THEORIES OF OWNERSHIP}

It was noted above that despite the lack of theoretical agreement as to what underlies the concepts of ownership and property, we nevertheless have an intuitive understanding of what these mean in practice. In other words, it could be said that we each have developed an implicit internal theory (or more probably an amalgam of theories) of ownership. For example, if someone unversed in philosophical theories of ownership is asked on what basis that concept rests then the answer will in all likelihood contain aspects of several of the theories described above. Indeed, the author has made just such an informal enquiry of a friend and received a reply that contained, in the first sentence, essential elements of both the first occupancy and labour theories.

Now, as noted above in the quote from Harris (1996), no single theory of ownership turns out to be completely satisfactory in the sense of being able to correctly account for our intuitive notions of ownership across all cases. The implication is that in resolving an issue of ownership we apply different theories, or at least aspects of them, according to context and circumstances. But what context and circumstances? First, an important aspect will be the perspective from which we view the ownership issue. What relationship do we have to the item for which ownership is being decided? More specifically, for example, were we the first to come across it? Did we create it? Do we have it in our possession? Second, what is the nature of the item for which ownership is being decided? Is it tangible or intangible? Are there existing and accepted precedents and conventions applying to the kind of object with which we are dealing that can guide and help in resolving ownership issues?

Since the target of interest to this paper is ownership as it affects data and information sharing, it is now necessary to turn to these, viewed from what might be called a "property" perspective. That is, in what ways, if any, are data and information similar to other things to which we normally ascribe ownership and, more particularly, how might the different ownership theories described above apply to them?

\section{DATA AND INFORMATION AS PROPERTY}

Can data and information be owned? It is often assumed so (e.g. Brynjolfsson, 1994), but it remains to ask in what ways are they are like and unlike other more traditional forms of property such as land and personal effects. Tackling differences first, unlike most "normal” items of property, data and information are typically characterised by:

- Intangibility - While data and information may be, and often are, instantiated in some tangible form such as hardcopy reports or computerised databases, it remains true that fundamentally they are intangible. It may be, for example, that I write the telephone numbers of my friends in a personal telephone book or store them in a personal organiser, but this is not an essential feature of this data or information. I could, if I'm good enough, simply commit them to memory and in such a case they are still the same data/information.

- Non-exclusivity - Unlike a physical object that can only be used (at any particular time) by its owner or someone to whom it has been temporarily loaned, use of data and information by one does not prevent its simultaneous use by another.

- Usage tolerance - Data and information do not (normally) deteriorate through use. There are, however, important exceptions to this. For example, insider knowledge of business performance data that will affect stock values cannot be used, at least by an arbitrary number of others, and remain completely unaffected by such use (Hettinger, 1989). 
- Age susceptibility - This characteristic is complementary to the usage tolerance aspect in that data and information often do deteriorate with age even if they have never been used. This is, again, to be contrasted with usual items of property for which this is not normally the case.

To the extent, then, that data and information exhibit these characteristics they are unlike usual items of property and therefore it may be expected that the concept of ownership should not apply to them, at least not in the same way that it applies to other items. However, in other important ways data and information do exhibit characteristics that permit the different theories of ownership to be applied to them.

In the first instance, it is possible for data and information to be discovered. Then, according to the first occupancy theory, being the discoverer confers ownership of the data or information that has been uncovered. Second, effort and resources are often expended in collecting data and producing information and therefore, according to the account of the labour theory, this should confer ownership of the result upon the producer. Third, the value of data and information is frequently if not always dependent on to whom and when it is available and the utility theory could therefore be applied in order to determine ownership from this value-based perspective. Fourth, data and information are often important enablers of personal or organisational activities that would not be possible in their absence. That is, they contribute to the liberty of the agent to pursue activities in an autonomous way, and therefore the libertarian theory could be applicable and used to determine ownership on this basis. Lastly, a distinction has for a long time been made in the information systems literature between data and information on the basis of purpose. As just one recent example:

"Information is data that has been refined and organised by processing and purposeful intelligence. The latter, purposeful intelligence, is crucial to the definition - People provide the purpose and the intelligence that produces true information” [emphasis added] (Whitten, et al, 2001).

It is clear that information at least (as opposed to data, which is considered its raw material) has purposefulness as one of its characteristics and for this reason the personality theory of ownership should be applicable to it.

To sum up: data and information have some characteristics that distinguish them from what we normally regard as items of property that can be legitimately owned. Nevertheless, there are also important aspects of them that are closely related to the various theories of ownership that emerge from the philosophical literature, and which allow the meaningful application of those theories in determining their ownership. Therefore, given that we each carry within us an implicit theory of ownership built around these philosophical foundations, that theory could in many respects be justifiably applied to considering who owns data and information.

\section{OWNERSHIP AND DATA AND INFORMATION SHARING}

In thinking about the implications of ownership perceptions for organizational data and information sharing it is perhaps necessary to first consider whose ownership perceptions are relevant. Ultimately organizations consist of individuals. However, in discussions of organizational behaviour it is groups as well as individuals that play a prominent role. What, then, of group versus individual perceptions of ownership? Indeed, is it meaningful to speak of a "group perception" at all? But this is not the place to enter such debates. It will instead be assumed in what follows that individual ownership perceptions are key, and where it might be meaningful to speak of a group's perception then this can be equated to a common set of individual perceptions across all of the members of that group.

We have seen that there are reasons for regarding data and information as being capable of being owned. However, depending on the (implicit) theory upon which one bases that ownership assessment as well as the perspective from which it is viewed, it may well be that a particular piece of data or information will turn out to have different owners. For example, a particular organisational group may have invested effort and resources in acquiring or generating certain data or information and therefore - on the basis of the first occupancy and labour theories - lay claim to it as its own. On the other hand, another organisational group (management, for example) might rightly see that the data or information concerned would provide them with substantial benefit for their purposes, and therefore - by the utility and personality and possibly libertarian theories - consider that its ownership legitimately resides with them.

In such a case, what would be the effect? To see this, consider again what ownership entails. It has already been seen that ownership confers certain rights; namely, and at the very least, the right to use, the right to control use, and the right to remain in control without interference from others. Therefore, where two or more different parties each see themselves as legitimate owners of particular data or information, albeit based on different underlying theories, it is natural to expect dispute and conflict concerning who should exercise these rights. In the example case above the original producers of the data or information - its actual possessors - would be expected to resist attempts by external parties to access and use it without their explicit consent. Moreover, they would also be expected to fight any attempts to wrest control of access or use from them, as well as viewing such attempts either to use or control use without their permission as unjustified interference with their ownership rights. On the other side, the other party would see such a response as entirely illegitimate, uncooperative and obstructive given their understanding that they are the valid owners of the data or information concerned. In their turn, they would not only seek to use the data or information as they saw fit (according to 
them they own it, after all), but would also seek to take control of it and regard attempts to block them in this as unjustified interference with their ownership rights. Conflict would be a natural outcome.

An analysis of this type could be applicable to, for example, the well-known FIS case study of Markus (1983) in which she describes the battle between divisional and corporate accountants over divisional finance data. While Markus describes the FIS case in power and political terms, the issue of ownership is nevertheless alluded to in her description. She says, for example: "Prior to FIS ... divisions retained control of their own data" whereas "after FIS ... the divisional accountants still had to enter the data, but they no longer 'owned' it" [emphasis added]. It is the contention of this paper that just such disputed ownership issues of the kind illustrated above may be a fundamental element underlying conflict, power and political situations of the type described in Markus’ paper.

\section{How Data and Information Sharing Can Occur}

If the analysis presented so far has any validity, it is reasonable to ask how it might account for the fact that data and information sharing occurs at all, under any circumstances. Manifestly, there are many situations in organisations where data and information are shared and this would seem to be at best incompatible with, and at worst destroy, the argument above. But there are at least two and possibly three responses to this.

First, the party that is the producer or possessor of data or information may deem itself, according to their implicit ownership theory, to be the legitimate owner of it but nevertheless consent to share it with various other parties. After all, one of the rights entailed in ownership is to control use of whatever is owned, and this includes allowing others to use it in circumstances considered appropriate by the owner. Second, even though one party may be the originator or possessor of certain data or information, their implicit ownership theory may tell them that its legitimate owner is in fact a different party and, therefore, not only should that data or information be shared with this other party, they should also cede the control the use of it to them. In both cases, the implicit ownership theories to which the involved parties subscribe do not serve to interfere with data and information sharing, but rather to further it.

A remaining possibility is that the implicit ownership theory of no party in the organisation leads it to lay claim to the data or information concerned. That is, everyone decides that ownership of it lies elsewhere and it is therefore someone else's prerogative to use it, and control its use. The data or information consequently remains unclaimed and uncontrolled, so anyone who wishes to can access and use it. It is, therefore, in a sense "shared" although in this case the term lacks the implication of intentionality it normally carries, that there is some (owning) actor actually initiating and doing the sharing.

\section{CONCLUSION}

Achieving data and information sharing in modern organizations has proven notably more difficult than expected despite the undoubted existence of technological capabilities to make it happen. One issue underlying these difficulties, it has been argued, is ownership perceptions on the part of organizational stakeholders (whose data or information is it anyway, and who therefore has the right to control it?).

The original foundations of ideas about ownership and property lie in considerations relating to land and physical objects and their long history of application in this domain has meant that there is now extensive intersubjective agreement, at least intuitively and taking due note of cultural context, as to how they work and when they apply. However, when intangible goods such as data and information, as captured and instantiated in modern computerized systems, are considered there is a much more abbreviated history and evidently less agreement as to who should own what, and on what grounds.

It has been argued in this paper that we carry "implicit” theories of ownership that contain elements from the various different philosophical bases that have been proposed as underlying the concepts of ownership and property in general, and it is on the basis of these implicit theories that we decide who legitimate owners are. Moreover, data and information, while different in a number of respects from traditional items of property, nevertheless exhibit important characteristics that make ownership theories applicable to them. Now the crux of the argument is that different parties within an organisation may, on the basis of their implicit theories of ownership and the particular characteristics of the data or information concerned as it relates to them, deem that ownership of it resides in different places. Ownership carries rights, notably those of use, control of use, and immunity from interference. Therefore, if different parties in the organisation each lay claim to ownership of the same data or information (albeit based on different grounds and perspectives) then conflict may arise over the exercise of these rights. Moreover, it has been argued that such differences of opinion over where ownership legitimately lies will potentially have important effects on sharing behaviour, although not necessarily so.

The contribution of this paper is that it illuminates the origin of organizational ownership norms with respect to data and information by applying philosophical theories of ownership more completely than has been done to date within the information systems literature. In doing so, it has drawn out more fully some reasons for information and data sharing behaviour, or the lack of it, in an organisational and information systems context. 


\section{REFERENCES}

Allen, D. K. \& Wilson, T. D. (1996) “Information Strategies in UK Higher Education Institutions”, Int. J. of Information Management, 16, pp 239-251

Applegate, L. M., Austin, R. D. \& McFarlan, F. W. (2003) Corporate Information Strategy and Management, $6^{\text {th }}$ ed, Boston: McGraw-Hill Irwin

Becker, L.C. (1977) Property Rights: Philosophic Foundations, Routledge \& Kegan Paul

Beynon-Davies, P. (2002) Information Systems: An Introduction to Informatics in Organsations, Palgrave

Brynjolfsson, E. (1994) “Information Assets, Technology, and Organization”, Management Science, 40, pp 1645-1662

Carter, A. (1989) The Philosophical Foundations of Property Rights, Harvester Wheatsheaf

Constant, D., Kiesler, S. \& Sproull, L. (1994) "What's Mine is Ours, or Is It? A Study of Attitudes about Information Sharing”, Information Systems Research, 5, pp 400-421

Davenport, T. H., Eccles, R. G. \& Prusak, L. (1992) “Information Politics”, Sloan Management Review, pp 53-65

Grunebaum, J. O. (1987) Private Ownership, Routledge \& Kegan Paul

Harris, J. W. (1996) Property and Justice, Clarendon

Hart, D. N. (1999) Ownership, Organizational Politics and Information Systems, PhD thesis (unpublished), UNSW - Australian Defence Force Academy;

http://www.library.unsw.edu.au/ thesis/adt-ADFA/public/adt-ADFA20020619.095737/

Hart, D. N. \& Whymark G. K. (1999) "Re-arranging the Chairs: Tackling the Ownership and Political Aspects of Organizational Transition and Information Systems Support” Proceedings of the $\mathbf{1}^{\text {st }}$ International Conference on Enterprise Information Systems, pp 453-461.

Hegel, G. W. F. (1821) The Philosophy of Right, trans T. M. Knox, reprinted in Hutchins, R. M. (1952) Great Books of the Western World, vol 46, Encyclopædia Britannica Inc

Hettinger, E. C. (1989) “Justifying Intellectual Property”, Philosophy and Public Affairs, 18, pp 31-52

Honoré, A. M. (1961) “Ownership” in A. Guest (ed) Oxford Essays in Jurisprudence, OUP

Jarvenpaa, S. L. \& Staples, D. S. (2000) "The Use of Collaborative Electronic Media for Information Sharing: An Exploratory Study of Determinants”, Strategic Information Systems, 9, pp 129-154

Keen, P. G. W. (1981) “Information Systems and Organizational Change”, Communications of the ACM, 24, pp 24-33

Kendall, K. E. \& Kendall, J. E. (2002) Systems Analysis and Design, $5^{\text {th }}$ ed, Prentice-Hall

Koh, C. E. \& Watson, H. J. (1998) “Data Management in Executive Information Systems”, Information \& Management, 33, 301-312

Liang, T. Y. (1996) “The Basic Entity Model: A Theoretical Model of Information Processing, Decision Making and Information Systems” Information Processing and Management, Vol 32, No 4, pp 477-487

Locke, J. (1689) “Of Property”, in C. B. Macpherson (ed), (1978) Property: Mainstream and Critical Positions, University of Toronto Press

Markus, M. L. (1983) “Power, Politics, and MIS Implementation”, Communications of the ACM, 26, pp 430444

Narveson, J. (1988) The Libertarian Idea, Temple University Press

Nolan, R. L. (1990) "Managing the Crisis in Data Processing” in The Information Infrastructure, Harvard Business Review

Nozick, R. (1974) Anarchy, State and Utopia, Basil Blackwell

Rawls, J. (1971) A Theory of Justice, OUP

Ryan, A. (1984) Property and Political Theory, Basil Blackwell

Ryan, A. (1987) Property, Open University Press

Schlatter, R. (1951) Private Property: The History of an Idea, George Allen \& Unwin

Stair, R.M. \& Reynolds, G.W. (1998) Principles of Information Systems: A Managerial Approach, $3^{\text {rd }}$ ed, Course Technology-ITP

Sterba, J. P. (1999) “Political Philosophy” in R. Audi (ed), The Cambridge Dictionary of Philosophy, $2^{\text {nd }}$ ed, Cambridge University Press

Van Alstyne, M., Brynjolfsson, E. \& Madnick, S. (1995) "Why Not One Big Database? Principles for Data Ownership”, Decision Support Systems, 15, pp 267-284

Waldron, J. (1988) The Right to Private Property, OUP

Whitten, J. L., Bentley, L. D. \& Dittman, K. C. (2001) Systems Analysis and Design Methods, $5^{\text {th }}$ ed, McGraw-Hill

Wigan, M. R. (1992) “Data Ownership” in R. Clarke \& J. Cameron (eds), Managing Information Technology's Organisational Impact, II, North-Holland 